\title{
Z-Source based Hysteresis Controlled AC to AC Converter for Wind Generation System
}

\author{
S.Balakumar \\ Research scholar, \\ Annamalai University, \\ Tamilnadu, India.
}

\author{
B.Baskaran \\ Professor, EEE dept, \\ Annamalai University, \\ Tamilnadu, India.
}

\begin{abstract}
This work deals with simulation of hysteresis controlled single phase AC-AC converter for wind generation. The AC output of the wind generator is converted into DC using three phase uncontrolled rectifier. The output of the rectifier is filtered using a Z-network. The output of the Z-network is applied to the single phase inverter. The single phase inverter feds an induction motor load. Matlab simulink model for wind generator system is developed and simulation studies are successfully performed. The simulation is done using MATLAB and the simulation results are presented.
\end{abstract}

Keywords: wind energy conversion system (WECS), AC-AC converter, MATLAB, Hysteresis controller,

\section{INTRODUCTION}

The rising rate of consumption of nuclear and fossil fuels has drawn worldwide attention to alternative energy technologies. In developed countries such as USA, European countries, wind power has been the fastest growing energy for the last decade, thanks to its increasingly attractive economics, its substantial environmental advantages, and supportive energy policies. However, it is in developing countries hybrid generation system in combination of wind and other renewable energies can play a major role to improve the quality of life of the people in the immediate future. Particularly in countries like India, Bangladesh, African, Latin America, many people live in isolated areas far from the main power utility grid. The inability of the electrical utilities meet their needs is a special concern to small rural based households, school and industries [1]. It has been proven that small-to-medium-size(10-100KW) hybrid generation systems based on wind and solar sources may meet the electricity requirements of lamps and small appliances, rural industries, community centers, health clinics, and schools[2].

In this international expanding context, research in the field of new technologies for Wind Energy Conversion Systems (WECS) and hybrid system has become central focal point. It has been established that together with the improvements in materials, Power Electronics, and blade design, the incorporation of advanced control system into the WECS is one of the major technology changes that has translated to reduced costs of energy [3], turning the development of highefficiency control strategies for WECS into an essential R\&D activity.

At present, such a control challenge can be tackled owing to the cost reduction and improvements of power semiconductors, AC drives and microprocessors. Despite the extra initial investment, the inclusion of electrical control permits a high degree of flexibility and more complex objectives can be achieved in variable speed operation control [4]-[7]. With technology improvements at hand, classic controllers for WECS can be updated by the development of more efficient strategies based on modern control techniques such as: fuzzy logic control, robust control and adaptive control. Among them Sliding-Mode (SM) control emerges as an especially suitable option to deal with variable speed operating WECS electronically controlled. This control technique has proven to be very robust with respect to system parameter variations and external disturbances. A deep look into the reasons exposed above clearly inferred that the development of novel control strategies for the grid-connected and stand-alone WECS is merely an area of research with plenty of challenging problems from the control design point of view, and principally a field of technological R\&D activity of high interest for environmental, social, economical and strategic reasons. The above literature does not deal with hysteresis controlled $\mathrm{Z}$ source inverter based $\mathrm{AC}$ to $\mathrm{AC}$ converter for wind generation. This work proposes hysteresis control for $\mathrm{AC}$ to $\mathrm{AC}$ converter of wind energy conversion system. The block diagram of wind energy conversion system is shown in Fig 1. The output of wind generator is rectified and filtered using a $\mathrm{Z}$ network. The inverter converts DC into fixed frequency AC and it feeds an induction motor load.

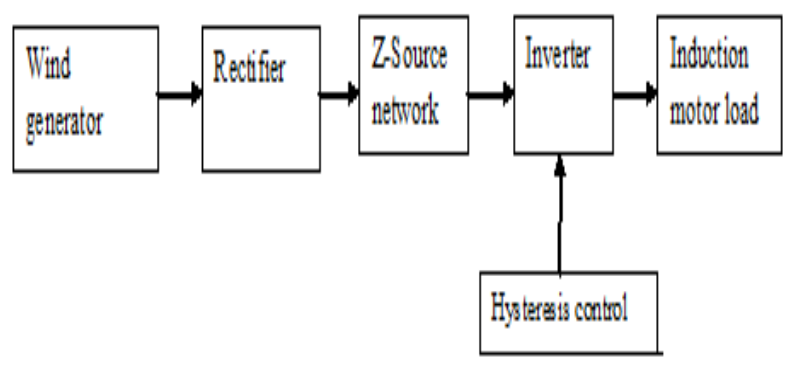

Fig.1. Block diagram of wind energy conversion system.

\section{Z-SOURCE NETWORK}

The traditional three phase voltage source inverter and three phase current source inverters have been widely used. They have some limitations and barriers that would finally limit the overall performance of the circuit and financially increased the system costs. Thus, the Z-source inverter has been proposed to overcome the limitations. The general structure of three phase Z-source inverter is shown in Fig.2. 
It basically has an impedance network that couple the converter main circuit to the power source. This addition of impedance network introduce a unique feature that cannot be used for the traditional three phase voltage source inverter and three phase current source inverter. The limitations for the traditional inverter are being solved in the z-source inverter. Fig. 2 shows a two-port network that consists of a split inductor $\mathrm{L}_{1}$ and $\mathrm{L}_{2}$, capacitors $\mathrm{C}_{1}$ and $\mathrm{C}_{2}$ connected in $\mathrm{x}$-shape to provide an impedance source coupling between the inverter and the DC source. The Z-source also can be used for all DC$\mathrm{DC}, \mathrm{AC}-\mathrm{AC}, \mathrm{AC}-\mathrm{DC}$ and $\mathrm{DC}-\mathrm{AC}$ power combinations.

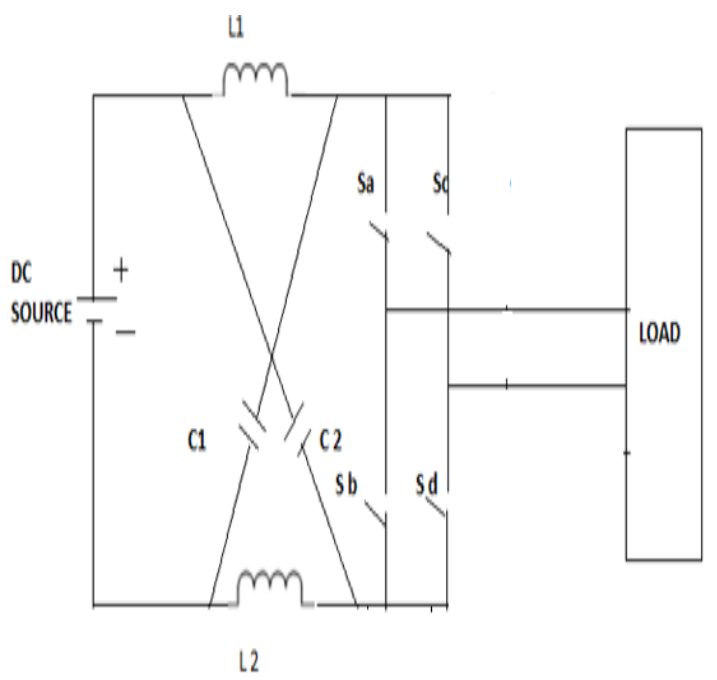

Fig,2. General structure of Z-source network

\section{PRINCIPLE OF HYSTERESIS CONTROL}

Hysteretic control is also called as bang- bang control. This mode of control helps to reduce steady state voltage fluctuations. It keeps ripple voltage within prescribed limits. The switches are turned on when the corresponding controlled parameter- either current or voltage -goes less than the lower limit. Similarly they are turned off when the parameter goes higher than upper limit.

A hysteresis controller is a feedback controller that switches abruptly between two states. These controllers may be used in terms of any element that provides hysteresis. They are often used to control a plant that accepts a binary input, for example a furnace that is either completely on or completely off. Most common residential thermostats are bang-bang controllers. Bang -bang controller also known as the optimal time controller since it has low response times.

The basic idea of DC voltage control with hysteresis controller is to replace reference DC voltage with a reference AC sinusoidal signal of required amplitude. Comparing the load current with the AC reference, the switching pulses are produced for inverter. The pulses are of the bipolar PWM form. At any given instant, when the load current is less than the reference signal, the forward switches of the inverter is on. If the current is higher than the reference sine, the reverse switches are on.

Compared to PI controller the steady state error is negligible. By using the filters, total harmonic distortion is reduced limit and a sine wave is obtained.

\section{DESIGN AND SIMULATION RESULTS}

The design of the elements of Z-Network is as follows:

Assumptions

$$
\begin{aligned}
& V_{i}=3000 \mathrm{~V} ; \Delta I=0.4 A ; f_{s}=3 \mathrm{KHZ} \\
& V_{O}=7000 \mathrm{~V} ; R=0.1 ; \\
& V_{O}=V_{I} / 1-D \\
& D=0.58 \\
& L=V_{I} \times D / f_{s} \times \Delta I
\end{aligned}
$$

$L=1.45 H$

$L=L_{1}=L_{2}=0.72 H$

$C=D /(2 f R)$

$C=966 \mu F$

$$
C=C_{1}=C_{2}=483 \mu F
$$

$$
T_{O}=1 / f_{o}=1 / 50=20 \mathrm{~ms}
$$

$$
P W=180^{\circ}, \quad \text { Pulse width }=10 \mathrm{~ms} \text {. }
$$

The simulation is done using the above parameters. The hysteresis controlled AC to AC converter system is modeled using the elements of simulink and it is simulated. The output voltage is sensed and it is compared with reference voltage. The error is given to hysteresis controller. This controller is proposed to minimize the fluctuations in output power. The measurement block of Wind Generation System (WGS) is shown in Fig 3b. The scope connected at the output is capable of measuring real power and reactive power. The output voltage of wind generator is shown in Fig 3c. The output of the rectifier is shown in Fig 3d. The output voltage of inverter is shown in Fig 3e. The current through the load is shown in Fig 3f. The current is inphase with voltage since the load is resistive load. The RMS output voltage is shown in Fig $3 \mathrm{~g}$. The output power is shown in Fig $3 \mathrm{~h}$. 


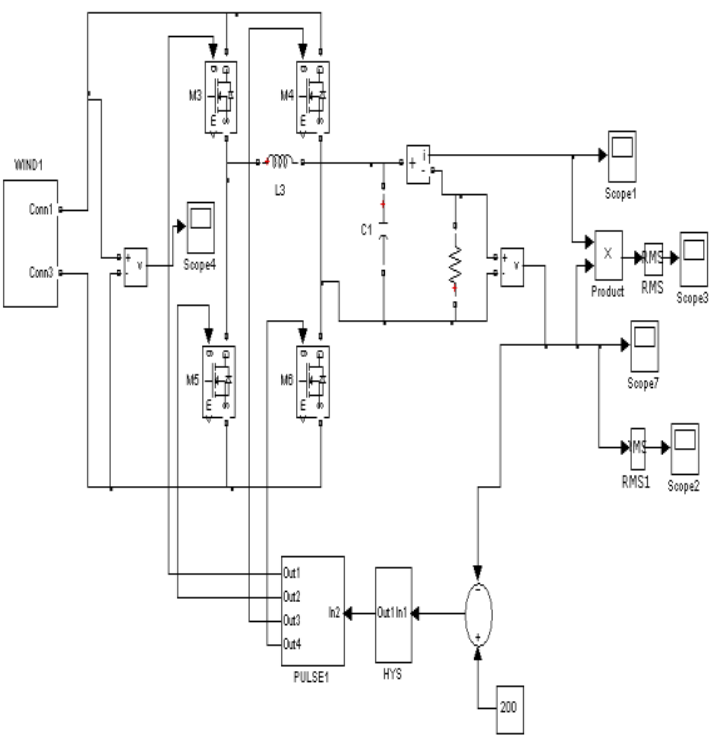

Fig 3a. Inverter system with hysteresis control

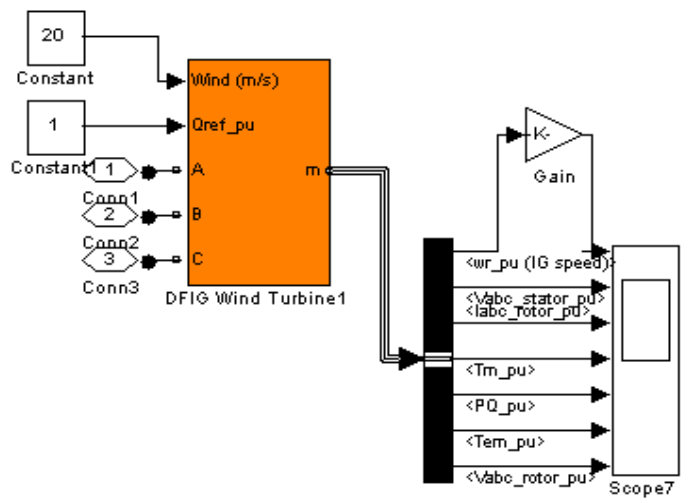

Fig.3b.Wind measurement system.

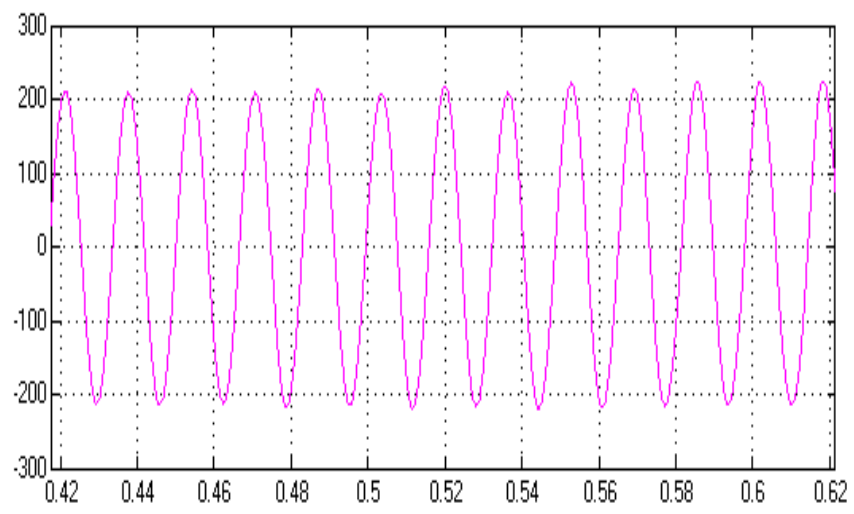

Fig 3c. Output voltage of wind generator.

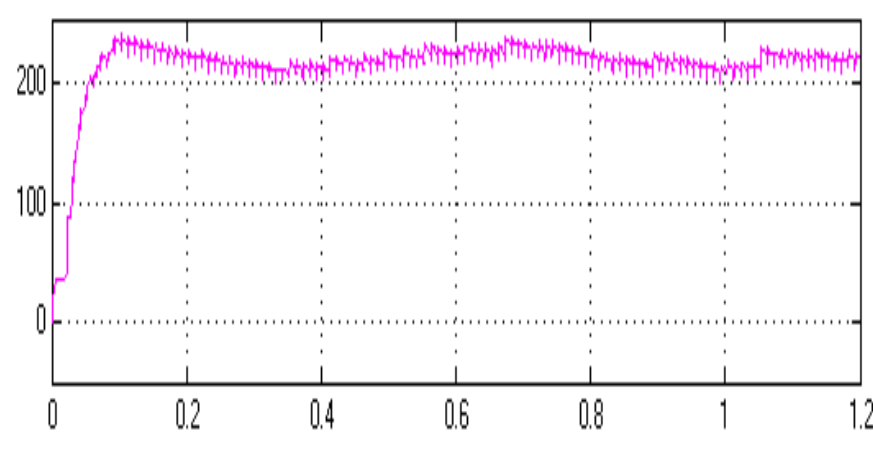

Fig.3d Output voltage of rectifier

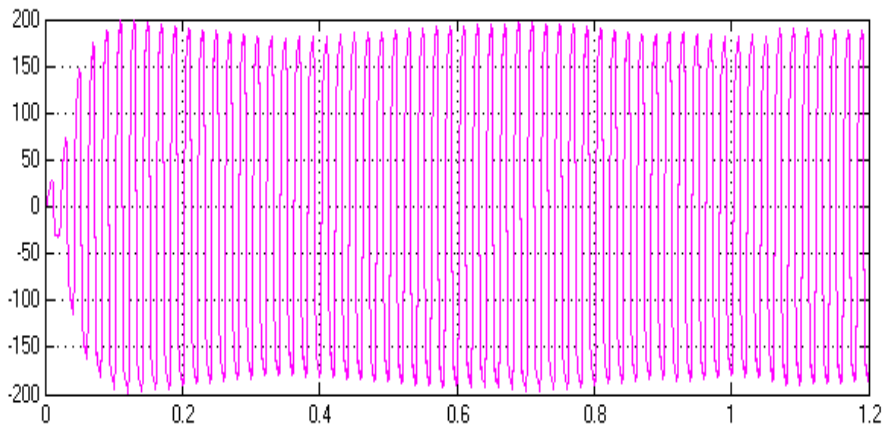

Fig 3e. Output voltage

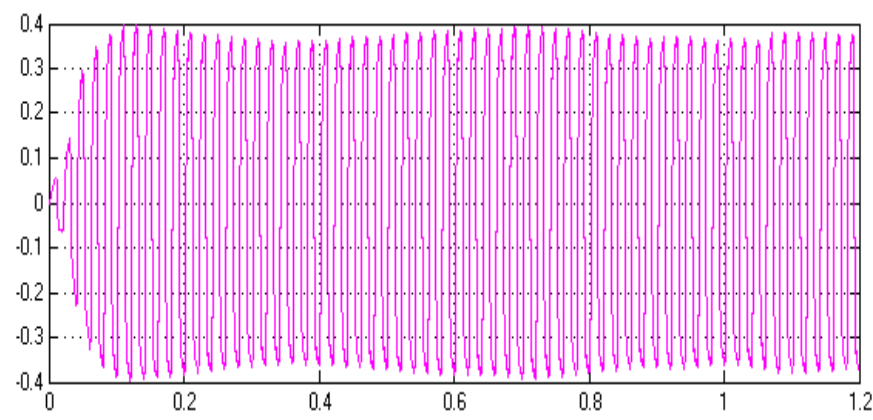

Fig 3f. Output current

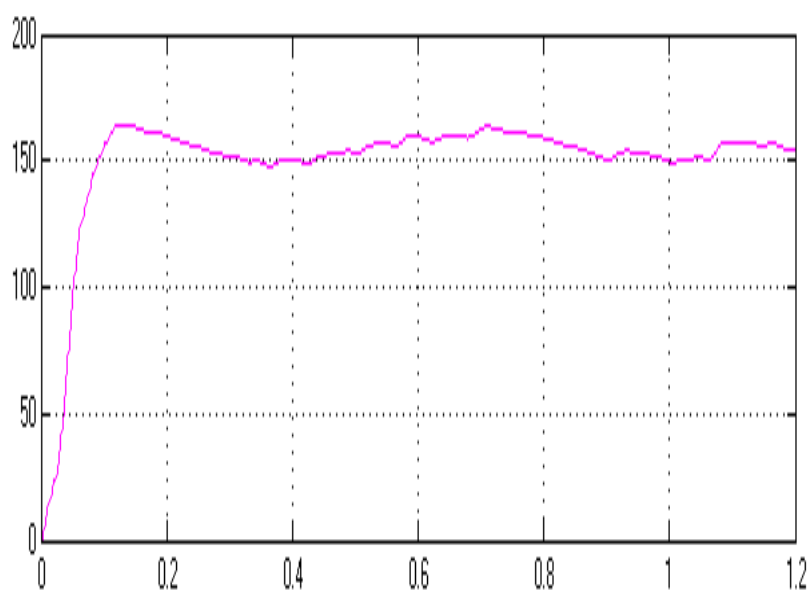

Fig 3g. RMS voltage 


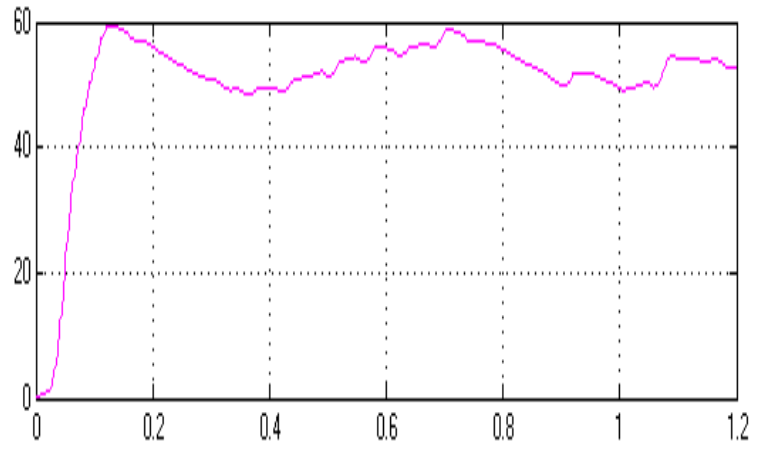

Fig 3h. Output Power

\section{CONCLUSION}

Hysteresis controlled Z-source based AC-AC converter for wind energy conversion is designed, modeled and successfully simulated using MATLAB Simulink . The Zsource network is capable of boosting low voltage from the wind generator to the rated level. The ripple in the output of the rectifier and the inverter is reduced by using Z-network. Thus the AC-AC converter is capable of converting the bad quality supply into good quality supply. The Simulink results are inline with the theoretical results. Z-source hysteresis controlled $\mathrm{AC}$ to $\mathrm{AC}$ converter may be recommended for wind systems to reduce the fluctuations in power.

The scope of this paper is the simulation of hysteresis controlled Z-source based AC-AC converter. The hardware will be implemented in future. The disadvantage of $\mathrm{Z}-$ network is that it requires two inductors and two capacitors.

\section{REFERENCE}

[1] R.Ramakumar, J.J.Bzura, J.Eyer, Guiterreez-Vera. T.E.Hoff, C.Herig, J.Iannucci and M.R.Milligan, "Renewable technologies and distribution system," IEEE Power Eng.,Rev.,pp.5-44,Nov.1999.

[2] J.Jadev, "Harnessing the wind" IEEE spectra., Vol.32, no.11, pp.78-83, Nov.1995.
[3] R.Swisher, C.Real de Azua, and J.Clendenin, "Strong winds on the horizon: Wind power comes of age," Proc, IEEE,Vol.89.no.12,pp.1757-1764,Dec.2001.

[4] R.Spee and H.Enslin,"Novel control strategies for variable speed doubly fed wind power generation systems,” Renew.Energy,vol.6,no.8,pp.907-915.

[5] P.Novak, T.Ekelund, Y.Jovik, and B.Schmidtbauer, "Modeling and control of variable-speed wind-turbine system dynamics, IEEE contr. syst. Mag., vol.15, no.4, pp.28-37, Aug.1995.

[6] T.Thringer and J.Linder,"Control by variable by variable rotor speed of fixed pitch wind turbine operating in speed range," IEEE Trans. Energyconvers., vol.8, no.3, pp.520526, Sep.1993.

[7] E.Muljadi, C.P.Butterfield, and P.Migluiore, Variable speed of Generator with Rotor Speed Feedback in Wind power Applications. National Renewable Energy Laboratory, Golden, CO.

[8] M.Gody Simoes, B.K.Bose, and R.J.Spiegei, "Fuzzy logic based intelligent control of a variable speed cage machine wind generation system," IEEE Trans. Power Electron. vol.12. no.1, pp.87-05, jan.1997.

[9] Dehghan.S.M, Mohamadian.M,Varjani.A.Y, “A new variable-speed wind energy conversion system permanent-magnet sysnchronous generator and z-source inverter," Energy conversion IEEE trans on vol.24, pp.714-724, 2009.

[10] Sharad W.Mohod Member, IEEE, and Mohan V.Aware, "Astatcom-control scheme for grid connected wind energy system for power quality improvement", IEEE system journal, vol.4, No.3, September 2010.

[11] Ramasamy.B.K, Palaniappan.A, Yakoh.S.M,’Diect-drive low-speed wind energy conversion system incorporating axial-type permanent magnet generator and z-source inverter with sensorless maximum power point tracking controller," Renewable power generation, IET vol.7, 2013. 